Original Research Article

\title{
A comparative study of efficacy of febuxostat and allopurinol regimens in patients of hyperuricemia
}

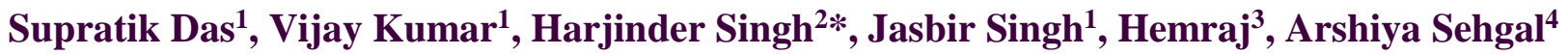

${ }^{1}$ Department of Pharmacology,

${ }^{2}$ Department of Urology,

${ }^{3}$ Department of Biochemistry,

Govt. Medical College, Patiala,

Punjab, India

${ }^{4}$ Medical Officer, General

Hospital, Narayangarh, Ambala,

Haryana, India

Received: 04 September 2017

Revised: 21 September 2017

Accepted: 27 September 2017

\section{*Correspondence to: \\ Dr. Harjinder Singh, \\ Email: dr.hsingh.uro@ \\ gmail.com}

Copyright: (C) the author(s), publisher and licensee Medip Academy. This is an openaccess article distributed under the terms of the Creative Commons Attribution NonCommercial License, which permits unrestricted noncommercial use, distribution, and reproduction in any medium, provided the original work is properly cited.

\begin{abstract}
Background: Gout, resulting from the precipitation of urate crystals in the tissues and the subsequent inflammatory response, causes an exquisitely painful distal monoarthritis alongwith joint destruction, subcutaneous deposits (tophi), renal calculi. The main culprit is uric Acid, which is a waste product formed due to purine metabolism. Gout Patients either produce excess Uric acid or are unable to excrete Uric acid produced in normal conditions. Uric acid lowering therapy (ULT) has become popular regarding management of gout. Nowadays. 2 drugs which are responsible for decreasing synthesis of Uric acid are Febuxostat and Allopurinol. The purpose of this study is to determine efficacy of Febuxostat and Allopurinol experienced by patients during course of therapy.

Methods: It was an open, prospective, observational, non-invasive, parallel and randomised study, conducted at the Outpatient Department of Urology, Rajindra Hospital, Patiala. It had 60 patients of gout, out which, 30 patients were administered Febuxostat and 30 patients were administered Allopurinol. For each patient, history regarding drug intake was taken, along with analysis of Serum Uric acid profile before prescription and during follow up.

Results: The mean age selected for study was 47 years for Febuxostat group and 43 years for Allopurinol group. Mean Urate $(\mathrm{mg} \%)$ in pre-treatment stage of patients of Febuxostat group is about 8.28 whereas for Allopurinol group its about 8.61. Mean urate levels after 4 follow ups (10 days each) were conducted. The mean Urate level at 10, 20,30, 40 days were conducted at each group which were found to be statistically significant and the results of Febuxostat group was found to be favourable.

Conclusions: Febuxostat, (40mg) given at daily dose was found to have higher efficacy than allopurinol, at a dose of $100 \mathrm{mg}$ (zyloric) which is the most commonly prescribed dose in order to lower the serum urate level.
\end{abstract}

Keywords: Allopurinol, Alloxanthine, Febuxostat, Gout, Uric acid, Xanthine oxidase

\section{INTRODUCTION}

Gout, an old known disease which was restricted upto the royalties, has broken itself from barriers of class and socioeconomic factors. Nowadays, it is the most common form of inflammatory arthritis in the elderly irrespsective of class and strata. ${ }^{1}$ Its name means 'drop' in Latin, thus implying that a toxin falling drop by drop at the joint tissue induced the disease. ${ }^{2}$ The current increment in the prevalence of gout is primarily due to changes in our lifestyle which consists of, lack of exercise, obesity, increased consumption of non-vegetarian foods accompanied with alcoholic beverages, specially Beer. These factors are solely behind the generation/progression of this disease. Many drugs are associated with decreased uric acid excretion, drug like thiazide diuretics, low-dose aspirin and cyclosporine have been a risk factor in the progression of this disease. ${ }^{3}$ Cardiovascular diseases can also be related with Hyperuricemia. ${ }^{4}$ Association of hypertension and renal pathologies also leads to an increased risk for Hyperuricemia. ${ }^{5-8}$ The term "Hyperuricemia" means that normal levels of Uric acid 
$(6.5 \mathrm{mg} / \mathrm{dl})$ gets exceeded, either due to overproduction of Uric acid or due to its under excretion, which ultimately may cause Gout. Uric acid on binding with Sodium leads to Sodium Urate production. ${ }^{9}$ In most of the mammals, uricase enzyme converts uric acid to allantoin which is soluble in nature; unfortunately, this enzyme is absent in humans due to the fact that the uricase gene is inhibited by 2 mutations that introduce premature stop codons, thus Gout victimises only humans. ${ }^{10,11}$

Gout consists of "Acute gout" showing self-limited attack of synovitis, called "gout flare". ${ }^{12}$ Its clinical manifestations comprise of acute gouty arthritis, gouty arthropathy, chronic tophaceous gout, uric acid urolithiasis, and gouty nephropathy, due to deposition of monosodium urate or uric acid crystals from supersaturated body fluids. ${ }^{13}$ Acute Gout shows recurrent attack of acute monoarthritis at the $1 \mathrm{st}$ metatarsophalangeal or tarsal joints resulting in acute redness along with tophus. Males are prone by four to nine fold whereas females suffer after menopause, due to loss of estrogen induced uricosuric action. ${ }^{14}$ The occurrence of the acute attack in male patients with a high BMI above 25 $\mathrm{kg} / \mathrm{m}^{2}$ is another feature which indicates gout. ${ }^{15}$ The solubility of Sodium Urate is influenced by numerous factors like $\mathrm{pH}$, temperature, sodium ion concentrations. ${ }^{16-18}$ also, factors like dehydration at joint tissues, nucleating factors like nonaggregated proteoglycans, insoluble collagens, and chondroitin sulfate play an important role in determining Uric acid solubility. ${ }^{19,20}$

Uric acid, a weak acid with a pKa of about 5.8 and existing as monosodium urate at physiologic $\mathrm{pH}$. Along with rise of urate concentration in body fluids, there is also risk for supersaturation and crystal formation. A direct positive association between serum urate levels and a future risk for gout has been established..$^{21,22}$

For diagnosis of Hyperuricemia, serum Uric acid level more than $7.06 \mathrm{mg} / \mathrm{dl}$ in males and more than $5.72 \mathrm{mg} / \mathrm{dl}$ in females alongwith presence of GFR having a value of about more than $60 \mathrm{ml} / \mathrm{min}$. Synovial fluid mat also be analysed in order to determine an impending risk of Uric acid crystal formation. ${ }^{14,15}$

Imaging techniques like Dual Energy CT Scan, Ultrasound also help in detecting the crystals. Whereas X Rays are used in recurrent attacks or in chronic gout. ${ }^{23,24}$

Initial therapeutic goal is rapid inhibition of an impending danger of pain and inflammation. A long-term goal consists of elimination of further attacks, tophi, and preventing joint destruction, by consistently reducing urate crystals concentration. ${ }^{25}$ Future prevention of attacks and other manifestations can be achieved only by reducing serum urate level. ${ }^{26}$

Most commonly used Pharmacological strategies is to reduce Urate production by inhibiting the function of Xanthine Oxidase enzyme which is a key enzyme in the production of Uric acid. Inhibition of Xanthine Oxidase leads to falling of excessive serum Uric acid level which has thus played a significant role in reducing the danger of crystal production and inflammation. Nowadays, a new drug called Febuxostat has also been known for showing more favourable effect in decreasing the formation of Xanthine Oxidase enzyme, thus proving to be more efficacious in preventing impending episodes of tissue inflammation. ${ }^{26,27}$

Table 1: A quick glance regarding the adverse effects and drug interactions shown by both the drugs.

\begin{tabular}{|c|c|c|}
\hline Properties & Febuxostat & Allopurinol \\
\hline $\begin{array}{l}\text { Adverse } \\
\text { effects }\end{array}$ & $\begin{array}{l}\text { Treatment-related adverse events consist of } \\
\text { nausea, vomiting, abdominal pain, joint related } \\
\text { adverse effects, abnormal liver-function test } \\
\text { results, headaches, and musculoskeletal signs } \\
\text { and symptoms. }{ }^{34}\end{array}$ & $\begin{array}{l}\text { Adverse effects comprise of, nausea, vomiting, } \\
\text { diarrhoea. peripheral neuritis, } \\
\text { necrotizing vasculitis, bone marrow suppression, and } \\
\text { rarely aplastic anemia. Also, Hepatotoxicity } \\
\text { interstitial lnephritis along with Pruritic } \\
\text { maculopapular lesions and cases of exfoliative } \\
\text { dermatitis may also be seen. Very rarely, allopurinol } \\
\text { may bind to the lens, resulting in cataracts. }{ }^{10}\end{array}$ \\
\hline $\begin{array}{l}\text { Drug } \\
\text { interactions }\end{array}$ & $\begin{array}{l}\text { Co-administration of Febuxostat with drugs who } \\
\text { use Xanthine Oxidase as substrate such as } \\
\text { azathioprine, mercaptopurine or theophylline } \\
\text { leads to increase in their plasma concentrations. } \\
\text { Since these drugs are unable to get metabolised } \\
\text { by xanthine oxidase, severe toxicity is } \\
\text { experienced. }{ }^{30} \\
\text { Febuxostat does not inhibit or induce } \\
\text { cytochrome } \\
\text { P450 enzymes, thus lacking significant drug } \\
\text { interactions with other drugs metabolized by }_{\text {these enzymes. }}{ }^{26}\end{array}$ & $\begin{array}{l}\text { Allopurinol increases the plasma concentration of } \\
\text { probenecid and enhances its uricosuric effect, while } \\
\text { probenecid increases oxypurinol clearance, thus } \\
\text { increased dose regimens of allopurinol are needed. } \\
\text { Allopurinol inhibits Xanthine Oxidase leading to } \\
\text { increased plasma concentrations of drugs like } \\
\text { azathioprine, Mercatopurine. It may also interfere } \\
\text { with metabolism of drugs like Warfarin. }{ }^{1}\end{array}$ \\
\hline
\end{tabular}




\section{Febuxostat}

This drug is a recently approved chemical entity, known as 2-[3-cyano-4- (2-methlypropoxy) phenyl]-4methlythiazole- 5-carboxylic acid. It acts as a non-purine, selective xanthine oxidase inhibitor and is administered at an oral dose of 80-120mg once daily and was discovered to be 10- 30 times more potent than allopurinol in preclinical studies. ${ }^{9,26-29}$ Its ki value is $0.7 \mathrm{nM}$ as compared to that of allopurinol $(0.7 \mu \mathrm{M})$ and has minimal effects on other enzymes involved in purine and pyrimidine metabolism. ${ }^{26}$ It is administered orally and shows rapid absorbtion, showing a Tmax of $1 \mathrm{~h}$ and is $99 \%$ bound to albumin alongwith low volume of distribution at steady state. Febuxostat is highly metabolized in the liver, to its acyl-glucuronide with the help of Cytochrome P450 enzymes. Less than $6 \%$ of the administered dose is excreted in the urine in its unchanged form. Its mean halflife is 4 to 9 h. ${ }^{30}$ No clinically significant effect has been found for food or antacids on its absorption. ${ }^{31}$

\section{Allopurinol}

It is the most commonly prescribed Xanthine Oxidase inhibitor, which is prescribed at recommended dose of 100-800mg/day. ${ }^{32}$ Allopurinol, chemically is known as an analog of hypoxanthine whereas its active metabolite, oxypurinol or alloxanthine, is an analog of xanthine. ${ }^{1}$ Allopurinol is given orally and is well absorbed. Its halflife is $2-3 \mathrm{~h}$ whereas its active metabolite alloxanthine has a half-life of 18-30 h. Renal excretion is shown by this drug and also shows a longer duration of action..$^{9,33}$

\section{METHODS}

\section{Place of study}

The study was conducted at the Outpatient Department of Urology, Government Medical College, Patiala, Punjab.

\section{Study design}

It was an open, prospective, observational, noninvasive,parallel and randomised study which comprised of total 60 patients diagnosed with hyperuricemia out which, 30 patients, consuming Febuxostat and 30 patients consuming Allopurinol were considered.

For each patient, proper history regarding the consumption of drug was taken, along with analysis of Serum Uric acid profile before prescription and during follow up. Other parameters consisting of Renal Function Test for Urea and Creatinine, Liver Function Tests, X-Ray films in order to observe the tophi, Routine tests and one scale regarding the diagnosis of Gout were considered and a questionnaire was also prepared.

Most commonly used scale regarding diagnosis of Gout is the one developed by the American Rheumatism Association in $1975:{ }^{35}$ It consists of the following criteria:

1. $>1$ attack of acute arthritis

2. Maximum inflammation developed within one day

3. Monoarthritis attacks

4. Redness observed over joints

5. 1st MTP (Metatarsophalangeal) joint painful or swollen

6. Unilateral 1st MTP joint attack

7. Unilateral tarsal joint attack

8. Tophus (proven or suspected)

9. Hyperuricaemia

10. Asymmetrical swelling within the joints on $\mathrm{x}$-ray

11. Sub-cortical cyst without erosion on x-ray

12. Monosodium urate monohydrate microcrystals in the joint fluid during an attack

13. Joint fluid culture negative for organism during an attack.

Table 2: Quality of life score in symptomatic patients of gout.

Questions
$\begin{aligned} & \text { Due to gout, how would you like } \\ & \text { to rate your health in past } 4 \\ & \text { weeks. }\end{aligned}$
$\begin{aligned} & \text { Due to Gout, how would you rate } \\ & \text { your quality of life in past } 4 \\ & \text { weeks. }\end{aligned}$
$\begin{aligned} & \text { Due to Gout, how would you rate } \\ & \text { weeks. }\end{aligned}$


Table 3: Symptom score index in patients of gout.

Due to gout, choose one option about how you have been doing since

the past 4 weeks:

$\begin{array}{llllllllll}\text { No disease activity } 1 & 2 & 3 & 4 & 5 & 6 & 7 & 8 & 9 & 10 \text { Severe disease activities }\end{array}$

Choose an option on the scale, indicating the severity of pain that you have experienced in the past 4 weeks:

$\begin{array}{llllllllll}\text { No pain } 1 & 2 & 3 & 4 & 5 & 6 & 7 & 8 & 9 & 10 \text { Severe pain }\end{array}$

Also, questionnaire consisting of self-reported questions for patients overall experience and impact of Gout symptoms have been introduced: ${ }^{36}$

\section{RESULTS}

Out of 60 patients enrolled for this study, 30 patients were administered Febuxostat whereas other 30 were administered Allopurinol. Observations found in this study were noted down in tabular form as given below.

Table 4: Account of the baseline variables involving patients who were involved in this study.

\begin{tabular}{|lll|}
\hline Variables & $\begin{array}{l}\text { Febuxostat } \\
\text { group }(\mathbf{n = 3 0})\end{array}$ & $\begin{array}{l}\text { Allopurinol } \\
\text { group }(\mathbf{n = 3 0})\end{array}$ \\
\hline Age (yrs) & $47.06 \pm 14.78$ & $43.70 \pm 14.46$ \\
\hline \multirow{2}{*}{ Gender } & $46.6 \%$ Females & $46.6 \%$ Females \\
\cline { 2 - 3 } & $53.4 \%$ Males & $53.4 \%$ Males \\
\hline
\end{tabular}

Result $=$ Mean \pm Standard deviation

Table 4 shows information regarding the variables regarding the patient/sample groups which were involved in this study. A total of 60 patients who were diagnosed with Hyperuricemia were selected for this study, out of which, 30 patients were administered Febuxostat and other 30 were administered Allopurinol. The mean age group of patients consuming Febuxostat were found to be $47.06 \pm 14.78$ yrs (Mean \pm Standard deviation) whereas, for Allopurinol group it was found to be $43.70 \pm 14.46 \mathrm{yrs}$.

The Gender distribution percentage in either of the groups were found to be same i.e. $46.6 \%$ females and $53.4 \%$ males

Mean results for data regarding pre-treatment Uric acid levels, were calculated and mean results regarding levels of Uric acid during follow up after 10 days, 20 days, 30 days and 40 days were calculated which was found to be significant. T-test was also conducted.

Table 5 shows that during the pre-treatment level, the mean level of Uric acid (Mean \pm Standard deviation) in Febuxostat group was found to be $8.28 \pm 0.53 \mathrm{mg} \%$ whereas for Allopurinol group it was found to be $8.61 \pm 0.93 \mathrm{mg} \%$. This was followed by follow up of respective groups, at $10,20,30,40$ days. During the course of the follow ups it was found that the group who had been consuming Febuxostat showed favourable decrease in the level of Uric acid as compared to that of the group where Allopurinol had been administered. At the end of 40 days, the mean
Uric acid level (Mean \pm Standard deviation) of the Febuxostat group was found to be $4.64 \pm 0.68 \mathrm{mg} \%$ whereas for Allopurinol group, it was $5.79 \pm 0.79 \mathrm{mg} \%$.

Table 5: Mean results obtained after comparing the two groups at their pre-treatment levels and after their drug administration and their follow up at 10, 20, 30, 40 days respectively.

\begin{tabular}{|lll|}
\hline Mean results & $\begin{array}{l}\text { Febuxostat } \\
\text { group }\end{array}$ & $\begin{array}{l}\text { Allopurinol } \\
\text { group }\end{array}$ \\
\hline $\begin{array}{l}\text { Pre-treatment Uric acid } \\
\text { levels (mg\%) }\end{array}$ & $8.28 \pm 0.53$ & $8.61 \pm 0.93$ \\
\hline $\begin{array}{l}\text { Uric acid level after 10 } \\
\text { days follow up (mg\%) }\end{array}$ & $7.08 \pm 0.55$ & $7.76 \pm 0.87$ \\
\hline $\begin{array}{l}\text { Uric acid levels after 20 } \\
\text { days follow up (mg\%) }\end{array}$ & $6.32 \pm 0.60$ & $7.09 \pm 0.83$ \\
\hline $\begin{array}{l}\text { Uric acid level after 30 } \\
\text { days follow up (mg\%) }\end{array}$ & $5.49 \pm 0.70$ & $6.42 \pm 0.83$ \\
\hline $\begin{array}{l}\text { Uric acid level after 40 } \\
\text { days follow up (mg\%) }\end{array}$ & $4.64 \pm 0.68$ & $5.79 \pm 0.79$ \\
\hline
\end{tabular}

Result $=$ Mean \pm Standard deviation

\section{Regarding T-test}

Table 6: Calculation of p-value and their results Uric acid value after follow up.

\begin{tabular}{|lll|}
\hline Parameters & p-value & $\begin{array}{l}\text { Highly significant/ } \\
\text { Non- significant }\end{array}$ \\
\hline $\begin{array}{l}\text { Pre-treatment uric } \\
\text { acid results }\end{array}$ & $>0.05$ & Non-significant \\
\hline $\begin{array}{l}\text { Uric acid level after } \\
10 \text { days follow up }\end{array}$ & $<0.05$ & Highly significant \\
\hline $\begin{array}{l}\text { Uric acid level after } \\
\text { 20 days follow up }\end{array}$ & $<0.0005$ & Highly significant \\
\hline $\begin{array}{l}\text { Uric acid level after } \\
\text { 30 days }\end{array}$ & $<0.0005$ & Highly significant \\
\hline $\begin{array}{l}\text { Uric acid level after } \\
\text { 40 days }\end{array}$ & $<0.0005$ & Highly significant \\
\hline
\end{tabular}

Table 6 shows, p-value obtained at the pre-treatment level was found to be $>0.05$ which was found to be Non significant but in case of follow up after 10, 20, 30, 40 days, p-value for uric acid levels was found to be $<0.05$, $<0.0005,<0.0005,<0.0005$ respectively i.e. highly significant. All these signify that proper randomisation during patient allotment was done. 


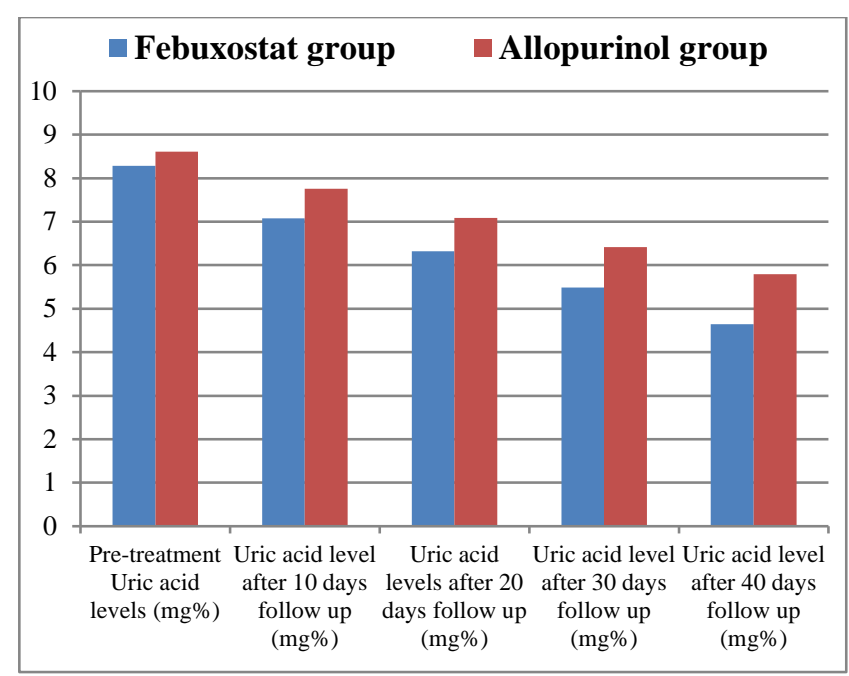

The mean changes in uric acid levels before and after administration of these drugs on each follow up has been depicted in the figure

\section{Figure 1: Comparing the efficacy of febuxostat and allopurinol in patients of hyperuricemia.}

At the mentioned in Figure 1, the Y-Axis denotes the level of Uric acid level in $\mathrm{mg} \%$ whereas the $\mathrm{X}$-Axis denotes the time period (days) during which, the follow up was conducted i.e. after 10, 20, 30, 40 days. At the graph, it can be seen that initially, the patient groups for Febuxostat and Allopurinol, having uric acid level at their pre-treatment levels are mentioned. The subsequent figures denote the falling level of Uric acid level in both the groups during each follow up time. The Blue bar depicting Febuxostat group show a favourable response as compared to that of Red bar for Allopurinol group because the Blue bar shows a greater fall in the Uric acid levels than the Red bar. Thus, showing a favourable response of Febuxostat over Allopurinol in lowering Uric acid levels.

\section{Adverse effects}

Out of 60 patients enrolled for the Comparative study between Febuxostat and Allopurinol, 3 patients reported with adverse effects which consisted of skin rashes which were of mild nature.

\section{DISCUSSION}

Gout is the commonest crystal arthropathy seen in clinical practice primarily affecting the joints and kidneys. Articular gout is divided into four clinical stages namely, asymptomatic hyperuricemia, acute gouty arthritis, intercritical gout and chronic tophaceous gout. Although it's not necessary that patients with hyperuricemia will develop clinical problems like gout or renal disease. The development of gout depends on factors like age of the patient and degree of hyperuricemia. Acute gouty arthritis generally is due to chronic hyperuricemia. It causes monoarticular or pauciarticular $(2,3$ or 4 joints $)$ involvement, and occasionally polyarthritis ( $>5$ joints) seen. Polyarticular disease is seen in the elderly and in postmenopausal women on diuretics. Intercritical gout refers to the symptom free period in between attacks. The second attack may never occur or occur after a variable period of time.

Diet and lifestyle management are some important baby steps in its management, protein intake restriction should be an important factor. Patients of gout should be encouraged to abstain from alcohol. Pharmacological management consists of Xanthine Oxidase inhibitors like Febuxostat and Allopurinol. Febuxostat, a new non-purine xanthine oxidase inhibitor and Allopurinol which is an analog of hypoxanthine, and its active metabolite, oxypurinol or alloxanthine, is an analog of xanthine and is routinely prescribed. Febuxostat was approved by the US FDA in February 2009 and is indicated in cases of: $:^{1,37}$

- Allopurinol hypersensitivity or intolerance

- Failure of allopurinol to normalize SUA

- CKD where the reduced allopurinol dose sub optimally controls SUA levels. ${ }^{29}$

In this study, it was found that a significant proportion of patients receiving Febuxostat had achieves a target serum Uric acid level of about $<5.0 \mathrm{mg} / \mathrm{dl}$ as compared to those receiving Allopurinol. Before the launch of Febuxostat there was only a single option of treating hyperuricemia with the help of Xanthine Oxidase inhibitors which was Allopurinol. The need for comparative study has emerged chiefly due to introduction of Febuxostat in order to help patients, providers and policy makers in making treatment decisions.

In this study total of 60 patients were selected out of which 30 patients were provided Febuxostat and 30 patients were provided Allopurinol. Average age group for febuxostat group and Allopurinol group was 47.06 $\pm 14.78 \mathrm{yrs}$ and $43.70 \pm 14.46$ yrs respectively whereas the pre-treatment levels of uric acid levels for febuxostat and Allopurinol group were $8.28 \pm 0.53 \mathrm{mg} \%$ and $8.61 \pm 0.93 \mathrm{mg} \%$ respectively. Febuxostat was provided at dose of $40 \mathrm{mg}$ and Allopurinol was provided at dose of 100mg. On keeping the duration of dose administration of both Febuxostat and Allopurinol same, it was found that Febuxostat leads to more efficacious lowering of serum Uric acid as compared to Allopurinol. This difference is both statistically significant and clinically meaningful because on conducting $\mathrm{T}$-test it was shown that the p-value of outcomes after 10days was $<0.05$ and for 20, 30, 40 days it was $<0.0005$ which depicts these results as highly significant.

\section{CONCLUSION}

In our study, it was found that Febuxostat was responsible for lowering the level of serum Uric acid much more efficiently than the currently used regimen of Allopurinol. Both treatment groups had patients of Hyperuricemia, whose preteatment levels of Uric acid was measured. After 10 days of providing treatment, the patients were follwed 
up and the same was performed after 20, 30 and 40 days of providing treatment. It was found that Febuxostat showed a dominant effect over Allopurinol, as the mean level of Uric acid was found to be $4.64 \pm 0.68 \mathrm{mg} \%$ in the Febuxostat group as compared to that of Allopurinol group which was about $5.79 \pm 0.79 \mathrm{mg} \%$. As discussed previously, p-value of outcomes after 10 days followup was $<0.05$ and for 20, 30, 40 days it was $<0.0005$ which indicates highly significant outcomes.

Since, the prime goal in treatment against Gout is reducing the level of serum Uric acid to normal level not only efficiently but also at the least possible time duration, we can say that Febuxostat, $(40 \mathrm{mg})$ given at daily dose reveals to provide higher efficacy than allopurinol, at a dose of $100 \mathrm{mg}$ (zyloric) which is the most commonly prescribed dose in order to lower the serum urate level.

Funding: No funding sources Conflict of interest: None declared

Ethical approval: The study was approved by the Institutional Ethics Committee

\section{REFERENCES}

1. Gilman A, Goodman L. Goodman's and Gilman's: The Pharmacological basis of Therapeutics: Antiinflammatory, Antipyretic, and Analgesic Agents; Pharmacotherapy of Gout: Introduction. $12^{\text {th }} \mathrm{Ed}$. The McGraw-Hill Companies, Inc; 2011.

2. Al-Allaf AW. Gout: evidence based update with new therapeutic strategies. Sudan Med J. 2012 Dec;48(3):165-75.

3. Kelly VM, Krishnan E. Febuxostat for the treatment of hyperuricemia in patients with gout. Int. J. Clin. Rheumatol. 2011;6(5):485-93.

4. Roubenoff R, Klag MJ, Mead LA, Liang KY, Seidler AJ, Hochberg MC. Incidence and risk factors for gout in white men. JAMA. 1991;266:3004-7.

5. Campion EW, Glynn RJ, DeLabry LO. Asymptomatic hyperuricemia. Risks and consequences in the Normative Aging Study. Am J Med. 1987;82:421-6.

6. Wyngaarden JB, Kelley WN. Gout and Hyperuricemia. New York: Grune \& Stratton; 1976.

7. Messerli FH, Frohlich ED, Dreslinski GR, Suarez DH, Aristimuno GG. Serum uric acid in essential hypertension: an indicator of renal vascular involvement. Ann Intern Med. 1980;93:817-21.

8. Oparil S, Zaman MA, Calhoun DA. Pathogenesis of hypertension. Ann Intern Med. 2003;139:761-76.

9. Sharma HL, Sharma KK. Principles of Pharmacology: NSAIDs, Drugs for Gout and Antirheumatoid drugs. 2nd ed. Hyderabad: Paras Medical Publisher; 2013.

10. Katzung BG, Masters SB, Trevor AJ. Basic and Clinical Pharmacology: Nonsteroidal AntiInflammatory Drugs, Disease-Modifying Antirheumatic Drugs, Nonopioid analgesics and Drugs used in Gout. $12^{\text {th }}$ Ed. New Delhi: Mc Graw Hill Education; 2012.
11. Wu XW, Lee CC, Muzny DM, Caskey CT. Urate oxidase: primary structure and evolutionary implications. Proc Natl Acad Sci USA. 1989;86:94126.

12. Khanna D, Khanna PP, Fitzgerald JD, Singh MK, Bae S, Neogi T, et al. American College of Rheumatology Guidelines for Management of Gout. Part 2: Therapy and Antiinflammatory Prophylaxis of Acute Gouty Arthritis. Arthritis Care Res. 2012; Oct;64(10):144761.

13. Wortmann RL. Gout and hyperuricemia. Curr Opin Rheumatol. 2002;14:281-6.

14. Malik A, Schumacher HR, Dinnella JE, Clayburne GM. Clinical diagnostic criteria for gout: comparison with the golden standard of synovial fluid crystal analysis. J Clin Rheumatol. 2009;15(1):22-4.

15. Janssen HJ, Fransen J, van de Lisdonk EH, van Riel PL, Janssen M. A diagnostic rule for acute gouty arthritis in primary care without joint fluid analysis. Arch Intern Med. 2010;170(13):1120-6.

16. Allen DJ, Milosovich G, Mattocks AM. Inhibition of monosodium urate needle crystal growth. Arthritis Rheum. 1965;8:1123-33.

17. Loeb JN. The influence of temperature on the solubility of monosodium urate. Arthritis Rheum. 1972;15:189-92.

18. Fiddis RW, Vlachos N, Calvert PD. Studies of urate crystallisation in relation to gout. Ann Rheum Dis. 1983;42:12-5.

19. Burt HM, Dutt YC. Growth of monosodium urate monohydrate crystals: effect of cartilage and synovial fluid components on in vitro growth rates. Ann Rheum Dis. 1986;45:858-64.

20. Fam AG, Stein J, Rubenstein J. Gouty arthritis in nodal osteoarthritis. J Rheumatol. 1996;23:684-9.

21. Campion EW, Glynn RJ, DeLabry LO. Asymptomatic hyperuricemia. Risks and consequences in the Normative Aging Study. Am J Med. 1987;82:421-6.

22. Lin KC, Lin HY, Chou P. The interaction between uric acid level and other risk factors on the development of gout among asymptomatic hyperuricemic men in a prospective study. J Rheumatol. 2000;27:1501-5.

23. De Miguel E, Puig JG, Castillo C, Peiteado D, Torres RJ, Martín-Mola E. Diagnosis of gout in patients with asymptomatic hyperuricaemia: a pilot ultrasound study. Annals of the rheumatic diseases. 2011 Sep.

24. Pineda C, Amezcua-Guerra LM, Solano C, RodriguezHenríquez P, Hernández-Díaz C, Vargas A, et al. Joint and tendon subclinical involvement suggestive of gouty arthritis in asymptomatic hyperuricemia: an ultrasound controlled study. Arthritis Research \& Therapy. 2011 Jan 17;13(1):R4.

25. Tausche AK, Jansen TL, Schroder HE, Bornstein SR, Aringer M, Ladner UM. Gout-Current Diagnosis and Treatment. Dtsch Arztebl Int. 2009;106 (34-35):54955.

26. Bisht M, Bist SS. Febuxostat. A Novel Agent for Management of Hyperuricemia in Gout. Indian $\mathbf{J}$ Pharm Sci. 2011 Nov-Dec;73(6):597-600. 
27. Reinders HK, Jansen TLTA. Management of hyperuricemia in gout: focus on febuxostat. Clinical Interventions in Aging. 2010;5:6-18.

28. Becker MA, Kisicki J, Khosravan R, Wu J, Mulford D, Hunt B, et al. Febuxostat (TMX-67), a novel, nonpurine, selective inhibitor of xanthine oxidase, is safe and decreases serum urate in healthy volunteers. Nucleosides Nucleotides Nucleic Acids 2004;23:1111-6.

29. Gout HR. Looking beyond Allopurinol. Medicine Update. 2010;20:822-5.

30. Cada DJ, Levien TL, Bake DE. Febuxostat. Hosp Pharm. 2009;44:688-99.

31. Khosravan R, Grabowski B, Wu JT, Joseph-Ridge N, Vernillet L. Effect of food or antacid on pharmacokinetics and pharmacodynamics of febuxostat in healthy subjects. $\mathrm{Br} \mathrm{J}$ Pharmacol. 2008;65:355-63.

32. Song GG, Lee YH. Comparative Efficacy and Safety of Febuxostat and Allopurinol in the Treatment of Hyperuricemia: A Bayesian Network Meta-analysis. J Rheum Dis. 2015;22(6):356-65.

33. Rang HP, Dale MM, Ritter JM, Flower RJ, Henderson G. Rang and Dale's Pharmacology: Anti inflammatory and immunosuppressant drugs. $7^{\text {th }}$ Ed. Livingstone: Churchill Elsevier; 2012.
34. Becker MA, Schumacher HR, Wortmann RL, MacDonald PA, Eustace D, Pala WA, et al. Febuxostat compared with allopurinol in patients with hyperuricemia and gout. $\mathrm{N}$ Engl $\mathrm{J}$ Med. 2005;353:2450-61.

35. Wallace SL, Robinson H, Masi AT, Decker JL, Mccarty DJ. Preliminary criteria for the classification of the acute arthritis of primary gout. Arthritis \& Rheumatology. 1977 Apr 1;20(3):895-900.

36. Sarkin AJ, Gnanasakthy A, Lale RS, Choi KJ, Hirsch JD. A Composite Endpoint Measure to Consolidate Multidimensional Impact of Treatment on Gouty Arthritis. Open Journal of Rheumatology and Autoimmune Diseases. 2013;3:159-64.

37. Edwards NL. Febuxostat: a new treatment for hyperuricaemia in gout. Rheumatology. 2009;48:ii159.

Cite this article as: Das S, Kumar V, Singh $\mathrm{H}$, Singh J, Hemraj, Sehgal A. A comparative study of efficacy of febuxostat and allopurinol regimens in patients of hyperuricemia. Int J Basic Clin Pharmacol 2017;6:2658-64 